\title{
THE FUTURE OF DWELLING: DENSITY
}

\author{
CAMILO CERRO \\ American University of Sharjah, UAE
}

\begin{abstract}
One of the most interesting and alarming characteristics of the Anthropocene has been the human migration trend from rural to urban areas, adding greater population to the cities. The United Nations estimates that $68 \%$ of the world's inhabitants will be living in urban areas by 2050 , with most cities illprepared to receive the newcomers. To adapt to the population increase, the cities have to either spread their footprint or become denser, with innovative urban strategies like smart growth implemented more in the developed world than the developing world. As the world population becomes increasingly urban, the challenge for designers will be to develop dwellings that are smarter and smaller to allow for an increase in density without losing public spaces, wasting energy or damaging the quality of life of its users. This paper will propose a new typology of sustainable, self-sufficient dwelling units, designed to create mixed age and socio-economical level communities in existing neighborhoods where building typologies have not changed much since the 1950s (in the USA). The basis for this next generation dwelling typology will produce a systemic interdependence between its functional and design elements by providing: spatial adaptability, production and filtration of water, generation of energy, urban farming and the interdependence of all these systems to sustain a live/work/farm environment in an affordable way that appeals to the consumer by bettering their quality of life and, at the same time, it does so while triplicating the population density per block. Right-sizing will be an essential aspect of this process, as we develop dwelling units designed to be versatile, adjustable, and user friendly. A process aimed at producing a housing typology re-designed for functional living, remote working and urban farming while providing dwelling solutions that allows for smart growth to shape the way urban density will manifest in the future.
\end{abstract}

Keywords: density, smart growth, live/work/farm, systemic interdependence, sustainable, selfsufficient, right-sizing.

\section{INTRODUCTION}

Between 1970 and 2015, the average size of newly constructed homes in the United States, increased by $79 \%$, from a size of 1,500 to 2,687 square feet. This increase in average home size did not correspond with an increase in household size. Its estimated that between 1970 and 2015 , the percentage of households with five or more members declined from $20.9 \%$ to $9.7 \%$, and the percentage of one-person households increased from $17.1 \%$ to $28.0 \%$ [1]. This shift has also redefined the definition of family unit and inherently, it has also redefined their habitation needs. With an estimated third of households in the United States, spending more than $30 \%$ of their income on housing [2], it is time for residential design to move in a more sustainable direction that looks into the future needs of the user and her/his community. On this paper we will focus on a proposal to implement a new typology of micro housing (live/work/farm) which will serve as a catalyst for smart growth in an inner city neighborhood within the United States. We will focus on the existing lot sizes to provide a mix use typology that triplicates the residential unit density of the typical city block. The idea is to create a systemic interdependence that will function at the micro and macro scales providing a housing typology re-designed for functional living, remote working and urban farming. Doing so in a sustainable self-sufficient way that uses smart growth concepts to transforms the block into a denser, greener and safer entity designed to better the quality of living of its users (Fig. 1) and the community as a whole. 


\section{FAMILY TYPES}

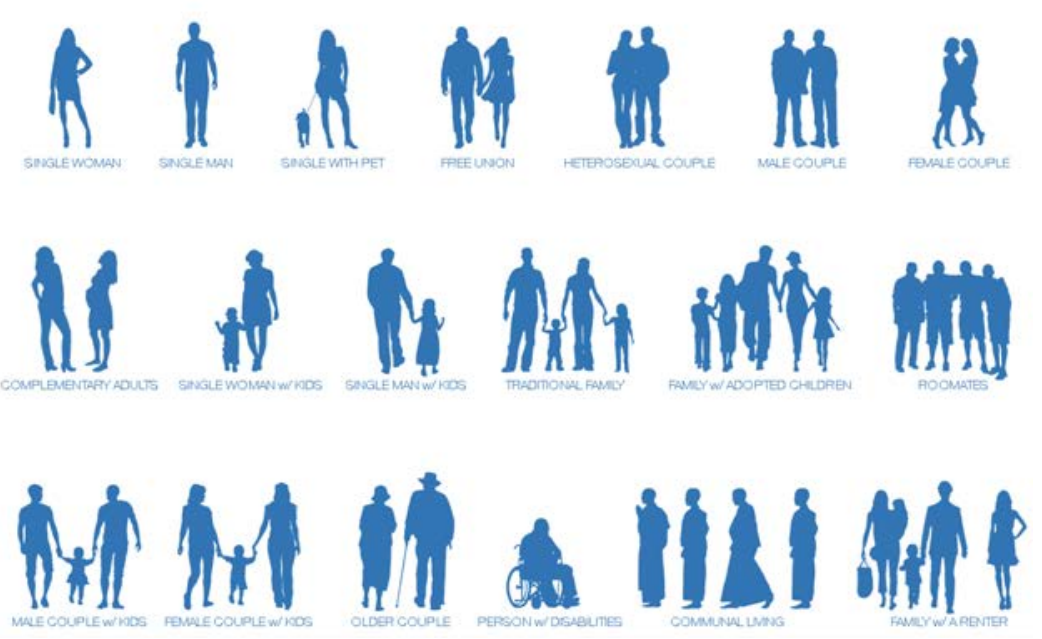

Figure 1: Family types - mixed use users.

\section{THE PROBLEM: A BRIEF HISTORY OF ZONING}

In the early 20th century, zoning regulations in the United States where mainly based on the authority of the city to be able to minimize the worst consequences of uncontrolled development. The idea was the separation of buildings to limit the spread of fire and to provide access to sunlight and air. The code later limited the height of buildings to the reach of local firefighting equipment and separated smoke producing industry from residential uses. This process was called separating incompatible land uses, which had as a result the present system of separating residential, commercial and industrial uses into distinct areas. For the purpose of this paper, we will only need to focus on the residential zones, and mainly on a specific land-use regulation that generated single family areas. The first example of which appeared in New York and Berkley in 1916 [3]. The reality was that besides arguments made for the reasoning behind this process, it was often the case that the original efforts to segregate land were more an elitist practice designed to protect property value than anything else. It wasn't until the 1950s that the problems with this practice started to be apparent. After the second world war, the return of the armed forces created an unprecedented demand for housing, which was meet with a zoning code that resulted in urban sprawl, giving way to expansive, decentralized residential areas which consumed large amounts of land, requiring infrastructure to spread further and further, and made public transport expensive and inefficient. This single-family lot regulation decided on a specific amount of land needed for a residential unit to occupy, and the sizes varied from locality to locality. Today, in a community like Lakewood in Los Angeles, the typical block has 38 houses per block, in a land grid that was designed in 1953, when the community was built. It comes as no surprise that houses have grown in size and cost over the last six decades, but have they changed much? In the 1950s, the average home was 1000 square feet [4], growing to an average size of 2500 square feet by 2017. In Lakewood the land divisions have remained the same as houses have expanded or have been rebuild, in some cases occupying the maximum allowed buildable area, resulting in less green spaces. Implementing an urban design proposal based 
on smart growth, a neighborhood like Lakewood could provide three times that number of residential units they presently have, increasing the urban density of the neighborhood.

\section{IS URBAN DENSITY GOOD?}

Urban density is considered an important factor in understanding how cities function. Since the 1970s, higher densities have come to be associated with a variety of indicators of environmental, economic, and social sustainability, including more efficient types of public services, infrastructure, lower environmental impact, and safer and more dynamic urban neighborhoods. Because of these, policymakers in the developed world are seeking to solve a number of perceived urban problems by increasing the intensity of urban land use. As the dwelling unit density increases above a certain threshold, it's been found that automobile usage and total distance traveled by car per household decreases and its substituted by public transport, cycling or walking [5]. The increased dynamism that results from the increase in dwelling unit density places more people in the public areas of the community, resulting among other things in a safer urban environment. And by consuming less rural land due to a denser urban fabric, the unused area can be used for agriculture or environmental preservation. But one of the most important factors that develop from denser neighborhoods comes in the form of financial savings as a result of not having to spread infrastructure away from the central facilities. But we have to be careful, because poorly managed density leads to overcrowding, a term generally linked to management and perception. The perception and tolerance for overcrowding is informed in part by cultural factors: Levels of acceptable density are perceived differently in Mumbai, New York and Copenhagen. But from a management perspective, overcrowding is the result of inadequate management of resources, services, transportation, infrastructure and housing. With this in mind, high-density, low-rise development are the ideal set up for urban layouts, striking a balance between efficiency and quality of life as long as they manifest together with a smart growth strategy.

\section{SMART GROWTH}

Smart growth is an urban development approach that encourages a mix of building types and uses, diverse housing typologies and transportation options, development within existing neighborhoods, and community engagement. And it was designed to generate denser walkable neighborhoods, help protect our health and natural environment and make our communities more attractive, economically stronger, and more socially diverse. In the 1990s the EPA (Environmental Protection Agency) developed the smart growth principles as an urban planning strategy to advocates focusing growth in compact livable communities to avoid sprawl. In 2006, the Smart Growth Network looked at the key characteristics that make successful communities and developed the following 10 basic principles:

- Mix land uses together.

- Take advantage of compact building design.

- Create a range of housing opportunities and choices.

- Create walkable neighbourhoods.

- Foster distinctive, attractive communities with a strong sense of place.

- Preserve open space, farmland, natural beauty, and critical environmental areas.

- Strengthen and direct development towards existing communities.

- Provide a variety of transportation choices.

- Make development decisions predictable, fair, and cost effective.

- Encourage community and stakeholder collaboration in development decisions. 
The approach followed on this paper will focus mainly on the second principle; "Take advantage of compact building design" by focusing on using micro-housing proposals to minimize the area occupied by a housing unit within its lot, intending to free more area for gardens and urban farming. This new dwelling typology will combine a live/work/farm scenario that will provide three times the housing density per lot in a mixed age dwelling design intended to better the quality of life of its users and the neighborhood as a whole.

\section{METHODOLOGY}

The mixed-use micro dwelling was designed to redefine an urban housing typology to adapt to the needs of urban life in the up and coming decades by generating a series of interdependent systems. Working at both the micro and macro scales, these series of projects main goal is to better the quality of life of the users and the local community around it by providing a dense, sustainable, mix use architectural typology that can be versatile and easily resized. The research was divided into three areas of study, going from what I am calling right-sizing which is defining the appropriate size of a micro dwelling in terms of a live/work/farm typology, to the interior and the active and passive technologies that can add to the quality of life premise, to the urban approach which defines the dwelling unit as part of a series of similar residences within a block designed to better the quality of life of the community. Although on this paper we are just covering the urban approach, all aspects of this research are interconnected and have been covered extensively on other papers. For the first two areas of study multiple designs were produced, one of which won an honorary mention in a competition sponsored by eleven magazines. This conceptual approach is also currently being implemented in the design and construction of two houses in the United States. Following you will find the overall methodology for the three aspects of the study:

Micro-houses:

- We started by looking at statistics from "the American time use" survey provided by the Bureau of Labor [6].

- We looked at the work presented by a UCLA team on the book "Life at Home in the Twenty-First Century: 32 Families Open Their Doors" [7] to define a planning strategy for the dwelling.

- An analysis of architectural precedent composed of residential design measuring between 400 square feet and 2000 square feet was stablished to provide case studies for the different interior and exterior elements of the dwelling. From this analysis a prototype kitchen was produced which won the research and development award at the "Reinventing Home Kitchen Design Competition", by Mia Cucina and Archiparti in Hong Kong, China.

- An analysis of type was produced to generate through it a design methodology.

- A design process was stablished with the aim to produce five distinct prototypes to address the live/work/farm typology.

- Designed a construction system to be prefabricated and easily installed in site.

- Researched new construction materials suitable for the project, assessing; Cost effectiveness, sustainability, carbon footprint, local availability and close loop potential.

- Researched different sustainable technologies to design the smart systems of the dwelling. This included: Hydroponics, aquaponics, mushroom farming, composting, energy production and storage, grey water filtering and reuse, 
water production through atmospheric water generators and sustainable thermal insulation.

- Developed a design strategy around the concept of systemic interdependency to have different elements functioning in a close loop to minimize the production of residual construction materials and try to reuse and recycle materials as much as possible.

Interior technologies:

- Researched new interior materials suitable for the project, assessing; Cost effectiveness, sustainability, carbon footprint, local availability and close loop potential.

- Researched and design systems of implementing hydroponics, aquaponics, mushroom farming, composting, energy storage, grey water filtering and reuse, water production through atmospheric water generators and sustainable thermal insulation as part of the built-in fixturing carpentry for the interior of the house.

- Developed a design strategy around the concept of systemic interdependency to have different elements functioning in a close loop to minimize the production of trash by the household.

- Designed an open plan strategy to allow for versatility and adaptability by the different users.

- Designed a storage strategy by using built in fixtures to control storage space to define the open plan strategy and house all the emerging technologies being used in the projects.

Urban approach:

- Conducted a thorough analysis of different approaches to dealing with the question of urban density by looking at an extensive number of case studies where we separated positive from negative outcomes in relationship to design parameters of the different projects.

- Developed a design strategy to implement smart grow ideas to generate an urban proposal based on the original micro dwelling research but for a mix use building designed to add density to the urban block.

- Choose possible sites in different localities where patterns of immigration show the need for higher density.

- Design an urban proposal using micro dwellings, that gives back more residential units and green space than the existing condition presently has using the existing land lot size as the generator of the design approach.

\section{MIXED USE LOW-RISE MICRO-HOUSING}

The research started by trying to generate a new dwelling typology (live/work/farm) that used emerging technologies to generate a better house designed to serve the user by: Generating its own energy, recycling or reusing grey water, composting organic trash and black water, producing its own water by using atmospheric water generators, producing a percentage of the household food through the use of hydroponics, aquaponics and/or mushroom farms, allowing for small industry and/or commercial spaces to exist as part of the household, be smaller on scale to spend less money in maintenance and energy consumption, be prefabricated, cost effective and to adder to the UN sustainable development goals.

Between 1970 and 2015, the average size of newly constructed homes in the United States, increased by $79 \%$, from a size of 1,500 to 2,687 square feet. This increase in average home 
size did not correspond with an increase in household size. Between 1970 and 2015, the percentage of households with five or more members declined from $20.9 \%$ to $9.7 \%$, and the percentage of one-person households increased from $17.1 \%$ to $28.0 \%$ [8]. With this in mind, we started by designing single family houses, formulated to occupy the same land lot as the houses built in the 1950s but reverting to a smaller built area dictated by micro home standards. This allowed us to have a framework from where to start designing. Eventually, once we had a micro house that fulfilled the systemic interdependence we were looking for, we started looking into the urban context to see if the same quality of life results produced at the dwelling level could be manifested into the urban block. By moving from the micro to the macro we started considering smart growth principles in search for sustainable urban density. To do this, we first had to make the building multi-unit to serve different generations of users. The proposal ended up combining different designs for micro dwellings, by stacking them vertically. The result (Fig. 2) is a four-story walk-up composed of two micro-apartments and a micro-duplex. The first floor is designed for one or two persons, with the elderly in mind because of its proximity to the street level. For the same reason, this first level could also serve as a commercial space. The second level, with a footprint and plan exactly like the first floor is meant to serve a single millennial user or a couple. The idea is that the size of the apartment is conducive for a couple but not a couple with children. For that we have the upper unit (duplex), which is designed for a couple with two children.

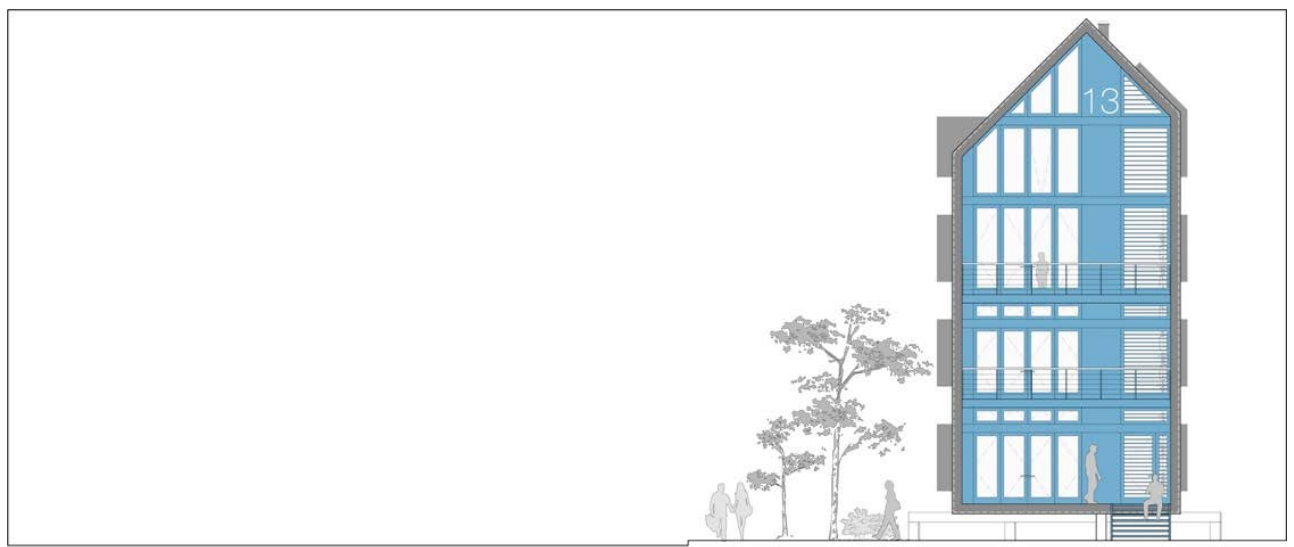

Figure 2: Front elevation at a mix-use micro house: first floor for the elderly or commercial, second floor for residents under 30 years of age, third and fourth floors (duplex) for a family of four.

Because the dwelling is designed as an extruded structure, the size of the dwelling is adaptable giving versatility to the usable size of the unit. A family can chose to add space to the building by elongating it longitudinally. The addition is cost effective, and it reuses existing elements as it is enlarged. The idea is that the building would be bought by the user of one of the units, renting the other two to offset the mortgage, or they would all be independently owned. The building is lifted of the ground by a spider structure, intended to allow for plant growth around and under the building. The system allows for a simpler and cheaper foundation which turns the block into a green space where the housing volumes float within. The first apartment has its access from the front terrace while the other ones use an 
exterior stair that also serves as a hydroponic farm for the unit. This large communal vertical hydroponic farm is meant to function seasonally. In addition each of the apartments counts with their own hydroponic system that functions all year around. As you go into any of the apartments (Fig. 3) you will find an open plan framed longitudinally by two long built-in fixtures. On one side a floor to ceiling fixture serves as a bookshelf, storage, work desk, with a large cubie/window that houses the dinning, one of the interior vertical hydroponic farming systems, and a Murphy bed on the opposite side of the open plan. The other wall has a deeper built-in fixture that houses the pantry, kitchen, another hydroponic farm, toilet, shower and closets. Both first and second floors share this layout which has a variation on the duplex where a living room is added instead of the Murphy bed and a stair takes the place of the shower, to take you to a second level with a master bedroom, two single rooms, a toilet, and shower. Through all the spaces the short sides of the open plan has floor to ceiling glassing with terraces at each side. A central core houses all the plumbing for bathrooms and kitchens together with all the equipment like: The solar batteries, atmospheric water generator, electric panels, etc. The unit has solar panels and solar water heaters on the roof, together with light tubes, and a water catchment system. Each of the units is prefabricated and designed to be lifted on top of each other on site.

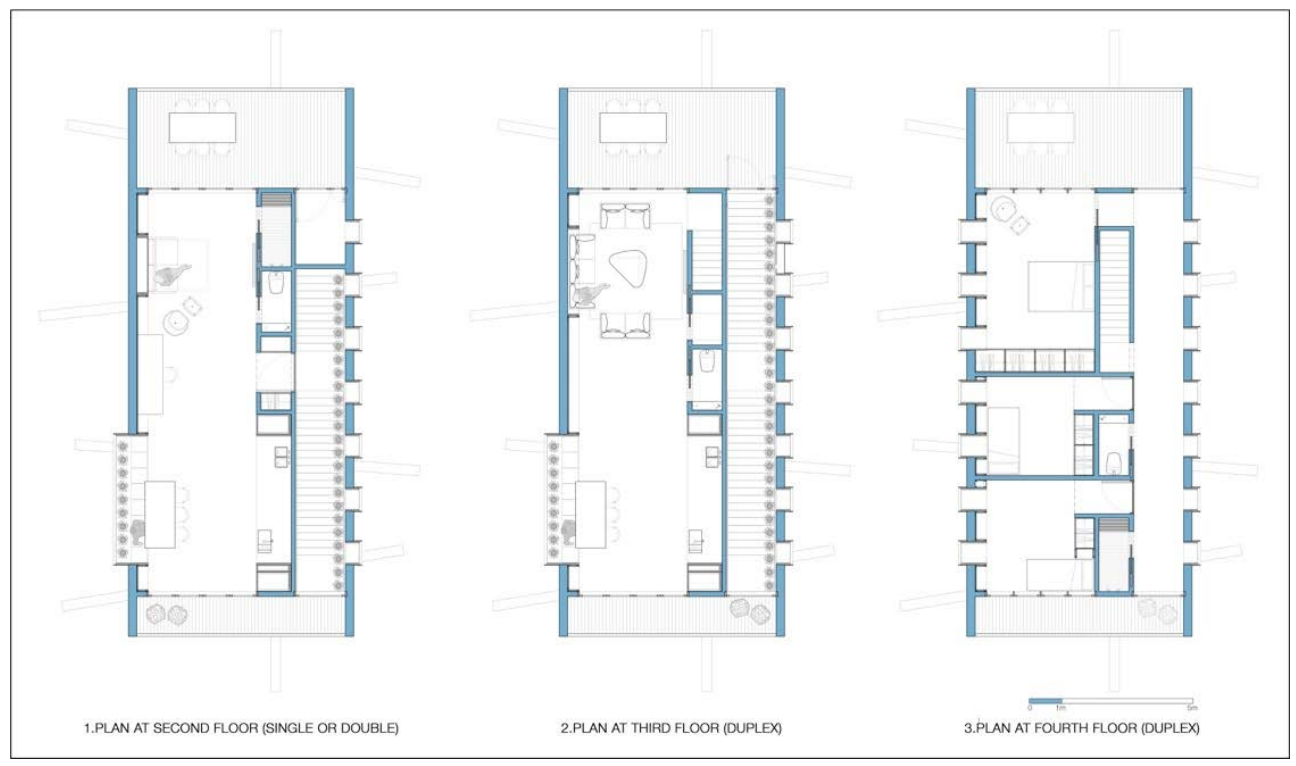

Figure 3: Plans at a mix-use micro house.

The first and second floors are 630 square feet $\left(58 \mathrm{~m}^{2}\right)$ of enclosed space with 285 square feet $\left(26 \mathrm{~m}^{2}\right)$ of terrace. And the duplex is 630 square feet $\left(58 \mathrm{~m}^{2}\right)$ on the first level and 830 square feet $\left(77 \mathrm{~m}^{2}\right)$ on the second level with 285 square feet $\left(26 \mathrm{~m}^{2}\right)$ of terrace. The whole building is ADA compliant by adding a wheelchair lift following the two sets of stairs.

But the Micro-House is much more than just a well-planned unit. It is estimated that by $2020,50 \%$ of the labor force of the developed world will be self-employed [9], turning their residences into mini factories where they will produce, package and sell products with the help of the internet and online marketplaces. The Micro-House versatility is designed to provide the adaptability needed to evolve with the needs of the user by turning the first or 
second floors into mini factories thanks to the open plan layout. In the long run, this proposal explores planning and design strategies that create an inclusive urban environment for the elderly while at the same time producing affordable dwelling proposals that increase the quality of life of the community by the use of emerging technologies.

\section{WHY ARE MICRO-HOUSES BETTER?}

So, at some point we had to answer this question. Why are micro-houses better? (Fig. 4) And in the present market of ecological awareness, financial incertitude and emerging technologies, the answer is simple:

- They are easier to maintain. The amount of time, energy and money that takes to maintain a house is directly related to its size.

- It takes less time to clean!

- Smaller homes are less expensive to purchase and less expensive in terms of: Insurance, taxes, heating, cooling, electricity, etc.

- Less debt and less risk.

- As is the case with all of our possessions, the more we own, the more they own us. Buying small is mentally freeing.

- A small house requires less resources to build and maintain producing less environmental impact.

- A small house results in more social interaction between its occupants.

- Moving into a small house forces you to decrease your possessions. And because room is limited you will not accumulate stuff you don't use.

- Less to decorate will allow you to choose carefully and save money.

- Many of the benefits stated will free up your time to do other things.

- And a smaller, more affordable house is affordable to a larger percentage of the population than a more expensive, less affordable one.
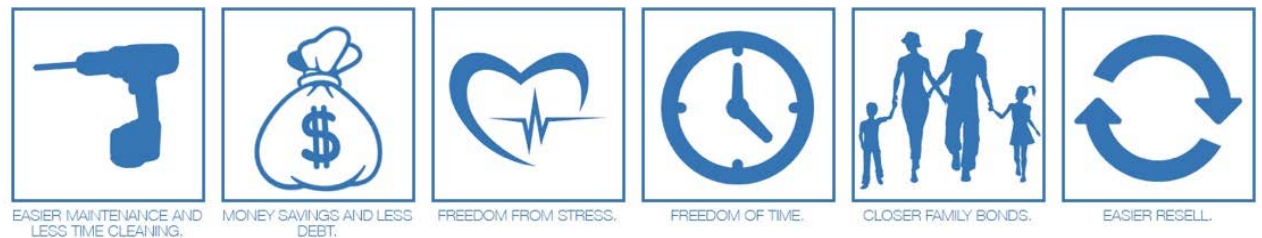

Figure 4: Why are micro-houses better?

\section{THE BLOCK AS AN URBAN ECOSYSTEM}

Urbanization presents fundamental challenges but also unprecedented opportunities to enhance the resilience and ecological functioning of urban systems. At the urban level a collection of micro houses using the existing lot regulations will produce a considerable amount of free space within the city block. We have already presented how density can work at the micro level when talking about the single building. At the macro level, this proposal has the opportunity to transform an existing block (Fig. 5), by using smart growth principles, into a sustainable, self-sufficient, denser, greener and safer entity. Rethinking green infrastructure has already shown how the creation of linked city ecosystems, encompassing: Parks, open spaces, urban trees, squares, woodland and waterways can help create healthier, more prosperous and safer cities. 


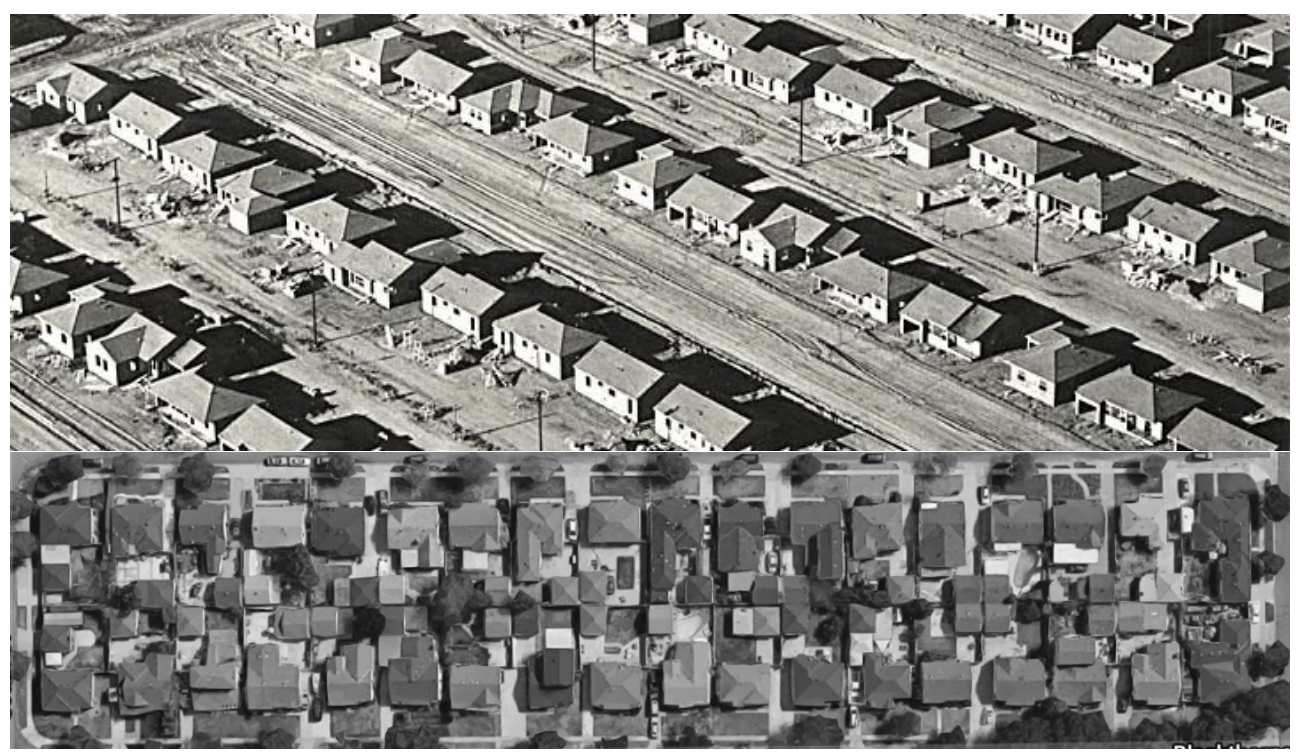

Figure 5: Top: a Lakewood being built in 1953. (Source: Estate of William A. Garnett.) Bottom: a typical Lakewood block, overcrowded with larger homes than intended and minimal green areas, today. (Source: Google maps.)

Despite significant challenges, cities are at the forefront of sustainability practice, at the center of which is the urban block. If we can transform the urban block into an urban ecosystem, the neighborhood will benefit in multiple ways: As climate change is producing more pluviosity, the interception of rainfall by trees, other vegetation, and permeable soils in urban areas can be crucial in reducing the pressure on the drainage system and in lowering the risk of flooding [9], Urban vegetation is widely reported to improve air quality while green area accessibility has been linked to reduced mortality [10] and improved perceived and actual general health [11], biodiversity in urban areas has a positive role in human well-being [12] and green spaces in urban areas have also been shown to influence social cohesion by providing a meeting place where users develop and maintain neighborhood ties. As we look towards the future of dwelling, we understand the interdependence between density and urban ecosystems, making it the next step to design a prototype.

\section{CONCLUSION}

To build a city that supports its citizens for decades to come, we need to identify how urban ecosystems work, how they change, and what limits their performance with the aim to design an architectural framework that supports an urban vision based on versatility and adaptability. A smart city should be designed to achieve holistic objectives, focusing on intelligent urban ecosystem designed to function at both the micro and macro levels. By $2050,70 \%$ of the global population will live in urban areas. Presently, cities worldwide are reshaping their urban ecosystems, often under the banners of sustainability and climate change resilient initiatives. With this in mind, the proposal presented on this paper was designed to take advantage of this trend by using emerging technologies and smart growth principles to propose a new typology (live/work/farm) of micro dwelling meant to address questions of urban density. Doing so by developing systemic interdependent planning paradigms, research 
methodologies and implementation processes to support higher population densities, higher standards of environmental sustainability, and enhanced the quality of life of the targeted communities.

\section{ACKNOWLEDGEMENT}

This research was supported by the College of Architecture, Art and Design (CAAD) at the American University of Sharjah.

\section{REFERENCES}

[1] Joint Center for Housing Studies, America's Rental Housing, Cambridge: Harvard University, 2017.

[2] US Housing and Urban Development, The case for small home design as a component of sustainability efforts. www.huduser.gov/portal/pdredge/pdr-edge-featd-article080816.html.

[3] Parolek, D., Parolek, K. \& Crawford, P., Form Based Codes; A Guide for Planners, Urban Designers, Municipalities and Developers, John Wiley: Hoboken, New Jersey, p. 7, 2008.

[4] Sparshott, J., US houses are still getting bigger, Wall Street Journal, 2 Jun. 2016.

[5] Newman, P. \& Kenworthy, J., Sustainability and Cities, Island Press: Washington DC, Ch. 3, 1999.

[6] Bureau of Labor Satatistics, 2017, American time usage survey. www.bls.gov/tus/ charts.htm. Accessed on: Oct. 2017.

[7] Arnold, J., Graesch, A., Ragazzini, E. \& Ochs, E., Life at Home in the Twenty-First Century: 32 Families Open Their Doors, 1st ed., The Cotsen Institute of Archaeology Press: USA,2012.

[8] Joint Center for Housing Studies, America's Rental Housing, Cambridge: Harvard University, 2017.

[9] Pataki, D.E. et al., Coupling biogeochemical cycles in urban environments: Ecosystem services, green solutions, and misconceptions. Frontiers in Ecology and the Environment, 9(1), pp. 27-36, 2011.

[10] Mitchell, R. \& Popham, F., Effect of exposure to natural environment on health inequalities: an observational population study, Lancet, pp. 1655-1660, 2008.

[11] Maas, J., Verheij, R.A., Groenewegen, P.P., de Vries, S. \& Spreeuwenberg, P., Green space, urbanity, and health: how strong is the relation? Journal of Epidemiology \& Community Health, 60, pp. 587-592, 2006.

[12] Fuller, R.A., Irvine, K.N., Devine-Wright, P., Warren, P.H. \& Gaston, K.J., Psychological benefits of greenspace increase with biodiversity. Biology Letters, 3(4), pp. 390-394, 2007. 